\title{
Documentos de política científica e educacional: convergências em torno da educação básica ${ }^{1}$
}

\author{
Scientific and educational policy documents: convergences around \\ basic education \\ Documentos de política científica y educacional: convergencias alrededor de la \\ educación básica \\ ADRIANO DE OLIVEIRA \\ LUCÍDIO BIANCHETTI
}

\begin{abstract}
Resumo: Com este texto analisamos as recomendações presentes nos Livros ('coloridos') Verde, de 2001; Branco, de 2002; e Azul, de 2010, que tratam de Ciência, Tecnologia e Inovação (C,T\&I), juntamente com o documento da UNESCO, Rumo às Sociedades do Conhecimento (2007). Estes convergem em relação à necessidade de que se desencadeie uma "revolução na educação básica", via fortalecimento da educação científica. Nessa conjuntura o CNPq amplia a capilaridade do fomento à pesquisa por meio da Iniciação Científica Júnior (ICJ).
\end{abstract}

Palavras-chave: Formação inicial de pesquisadores; ICJ; educação básica.

\begin{abstract}
In this article we analyze the recommendations found in the ("colored") books Verde (2001); Branco (2002); and Azul (2010) about science, technology and innovation, as well as the UNESCO document, Towards Knowledge Societies (2007). Both the books and the UNESCO document converge in relation to the need of stimulating a "revolution in basic education" by strengthening scientific education. In this conjuncture, CNPq expanded the capillarity of its support to research through the Junior Scientific Initiation Program.
\end{abstract}

Keywords: Initial education of researchers; junior scientific initiation; basic education.

Resumen: Con este texto analizamos las recomendaciones presentes en los Libros ('coloridos') Verde, de 2001; Blanco, de 2002; y Azul, de 2010, que tratan de Ciencia, Tecnología e Innovación (C, T\&I), juntamente con el documento de la UNESCO, Rumbo a las Sociedades del Conocimiento (2007). Ellos convergen con relación a la necesidad de que se desencadene una "revolución en la educación básica", vía fortalecimiento de la educación científica. En esa coyuntura el CNPq amplía la capilaridad del fomento a la investigación por medio de la Iniciación Científica Júnior (ICJ).

Palabras clave: Formación inicial de investigadores; ICJ; educación básica.

1 Uma versão deste texto foi apresentada no V Congresso Ibero-Americano e VIII Congresso LusoBrasileiro, ocorrido na Pontifícia Universidade Católica de Goiás (PUC-GOIÁS), em Goiânia/GO, ocorrido entre 14 e 16 de setembro de 2016. 


\section{INTRODUÇÃO ${ }^{2}$}

Neste artigo, objetivamos analisar o conteúdo e o significado político, econômico, social e educacional dos conceitos e de algumas prescrições presentes nos Livros Verde 3 , de 2001, e no Branco, de 2002, que tratam de C,T\&I, lançados no final do governo Fernando Henrique Cardoso (1995-2002). Procedimento similar foi adotado em relação ao Livro Azul, de C,T\&I, publicado em 2010, no final do Governo Luiz Inácio Lula da Silva (2003-2010). Essas obras resultaram de um processo cuja finalidade foi analisar e implementar políticas científicas, tecnológicas e educacionais para os anos que se seguiram aos mandatos desses governantes. Também analisamos o Relatório Mundial da United Nations Educational, Scientific and Cultural Organization (UNESCO), de 2007, "Rumo às Sociedades do Conhecimento", coordenado por Jérôme Bindé (2007). Nesse documento, procuramos identificar alguns dos pressupostos teórico-ideológicos que fundamentam o discurso das Sociedades do Conhecimento, existentes nos documentos brasileiros mencionados. E com esse pano de fundo, visamos, precipuamente, focar a forma como nossa temática de pesquisa, a iniciação científica na Educação Básica (EB), está diretamente imbricada com essas discussões e implementações.

\section{OS PRESSUPOSTOS TEÓRICO-IDEOLÓGICOS DAS CHAMADAS 'SOCIEDADES DO CONHECIMENTO'4}

O Relatório Mundial UNESCO, aqui focado, resulta do trabalho da comissão coordenada por Jérôme Bindé, que discutiu as perspectivas de constituição das denominadas Sociedades do Conhecimento. À época, parecia haver uma convergência no sentido de que "não há mais como postergar a entrada na Sociedade do Conhecimento" (BIANCHETTI; QUARTIEIRO, 2011,

\footnotetext{
2 Subtraímos aqui informações a respeito das origens deste texto, uma vez que podem levar à quebra do anonimato.

3 A designação de documentos de política científica e educacional por "livros verdes, brancos e azuis" não é uma criação dos Governos Fernando Henrique Cardoso e Luiz Inácio Lula da Silva. Originou-se na Comunidade das Nações, nos Estados Unidos e na União Europeia. Pelas cores identificam-se diferentes fases de uma política. Por exemplo, no Brasil, o Livro Verde (2001) serviu para subsidiar os debates da Conferência Nacional de Ciência, Tecnologia e Inovação, o Livro Branco (2002) expressa os resultados da Conferência, apresentando as diretrizes e as recomendações para a área. Já o Livro Azul (2010) foi dividido em dois volumes, o primeiro sintetizando as ideias-força que surgiram da $4^{\text {a }}$ Conferência Nacional de Ciência, Tecnologia e Inovação (CNCTI) e o segundo volume apresentando as recomendações.

No relatório Bindé (2007, p. 22) o conceito fulcral é "sociedades" do conhecimento, pois na constituição das sociedades há "várias formas de conhecimento e cultura". Portanto, existe uma diversidade de sociedades do conhecimento.
}

152 - RBPAE - v. 33, n. 1, p. 151 - 166, jan./abr. 2017 
p. 143). Um dos pressupostos dos elaboradores desse documento da UNESCO - em uma explícita perspectiva determinista tecnológica - é que as Tecnologias Digitais (TD) foram as responsáveis pela introdução de grandes transformações nas relações sociais, por exemplo, no âmbito da produção, da educação e da ciência. Porém, no Relatório Bindé há o reconhecimento das desigualdades de acesso às Sociedades do Conhecimento entre países - inclusive intra - e blocos político-econômicos do norte e sul do planeta. Com base no diagnóstico dessas diferenças, os formuladores do documento apresentam uma visão prospectiva para a superação das desigualdades na aquisição da informação e do conhecimento, fundamentada na crença da possibilidade de ampliação mundial das Sociedades do Conhecimento, por meio "da difusão generalizada do conhecimento" (BINDÉ, 2007, p. 278).

No Relatório Bindé há uma diferenciação entre informação e conhecimento, pois se afirma que a sociedade da informação é baseada no progresso tecnológico e as sociedades do conhecimento "abrange[m] dimensões sociais, éticas e políticas bem mais vastas" (Idem, p. 22). Dessa forma, há um processo reflexivo "para converter informação em conhecimento" que "significa que este processo envolve mais do que uma mera verificação dos factos. Implica saber dominar certas aptidões cognitivas, críticas e teóricas" (Idem, p. 78).

Nesse contexto, "ninguém deveria ser excluído das sociedades do conhecimento", porque esse é um bem público e, como tal, necessariamente disponível para todos (Idem, p. 23). Porém, no Relatório, há o reconhecimento da comercialização do conhecimento com o predomínio dos objetivos "de rentabilidade a curto prazo" prevalecendo "sobre os propósitos da investigação pública" e da divisão internacional do trabalho, o que "confina as atividades de investigação aos países mais ricos” (Idem, p. 177-179) do eixo norte do planeta. Essa desigualdade econômica é justificada pela anomalia dos mercados e pela divisão internacional do trabalho e não por meio da produção e do uso da C,T\&I para garantir o processo de acumulação do capital, portanto, de superexploração do trabalhador.

A fim de superar essas desigualdades no acesso ao conhecimento e às TD, recomenda-se a priorização da educação e da ciência voltadas para o desenvolvimento humano e sustentável. Para isso, preconiza-se ser necessária a constituição de "sistemas nacionais de investigação e inovação, que, por sua vez, resultam da interação entre empresas, indústrias, instituições científicas de investigação e ensino e organizações governamentais" (BINDÉ, 2007, p. 170). Aqui podemos perceber a tentativa de mobilização de vários setores da sociedade para o estabelecimento das políticas e sua concretização, produzindo consenso em torno da concepção das Sociedades do Conhecimento. O que se propõe 
é maior integração das políticas do conhecimento, envolvendo a educação, a ciência, a tecnologia e a inovação. A finalidade é integrar essas áreas "numa política coerente de desenvolvimento científico e econômico, para favorecer a melhoria das tecnologias existentes e incentivar a assimilação de tecnologias novas e estrangeiras" (Idem, p. 180). Essa posição aponta, para os países fora do polo dinâmico do capital, a incorporação e assimilação das tecnologias advindas dos países que dominam tecnologias de ponta, prescrevendo-se, portanto, uma inserção subordinada nas chamadas "Sociedades do Conhecimento".

O que se propõe, no Relatório Bindé, é a constituição de uma cultura permanente de inovação e renovação, pois "conhecimentos, técnicas e instituições vão sentir-se cada vez mais ameaçadas com a pressão da obsolescência." A “cultura já não se constrói a partir de esquemas de permanência e produção repetitiva, mas de criatividade e renovação" (Idem, 2007, p. 95). Para os países do eixo sul, a qualidade da intervenção humana é intensificada "como requisito para o uso de novas tecnologias e com comportamento 'inovador" e "os sistemas educacionais devem dar respostas a essa necessidade" (NOMA; KOEPSEL; CHILANTE, 2010, p. 76), preparando mentes e corpos para o processo de acumulação flexível.

Outro princípio estruturante do Relatório Bindé e pressuposto das Sociedades do Conhecimento é o aprender a aprender, que "significa aprender a pensar, duvidar, adaptar o mais rapidamente possível e ser capaz de questionar a nossa herança cultural paralelamente a respeitar consensos" (BINDÉ, 2007, p. 103). A pedagogia do aprender a aprender "é claramente voltada à preparação dos indivíduos para a sociedade onde se aprende por conta própria, para a convivência pacífica com as condições vigentes, através do desenvolvimento de suas capacidades adaptativas" (MARI, 2006, p. 168). Para o desenvolvimento dessa habilidade é fundamental a educação científica e tecnológica direcionada à aplicação do conhecimento na resolução de problemas do cotidiano, num ambiente de intensificação do uso das TDs nos processos de produção de mercadorias; portanto, uma formação voltada à ação do fazer. Além disso, é proposta, no Relatório, a "educação ao longo" da vida, que continua a ser, segundo os formuladores do documento, a melhor garantia para que os estudantes continuem seus percursos educativos em cenários formais e informais, e uma solução para a volatilidade do trabalho (BINDÉ, 2007).

Nesse sentido, a educação científica e a iniciação científica (IC) podem contribuir para o desenvolvimento da habilidade de resolução de problemas, característica de uma posição pragmática e utilitária, tendo em vista que "todos devem ser capazes de se movimentar facilmente através da corrente de informação que nos envolve e a desenvolver capacidades de raciocínio cognitivo e crítico de modo a distinguir entre formação 'útil' e 'inútil'." (Idem, p. 26). 
Outra prescrição à escola e à universidade, presente no Relatório, é formar muitos professores "de elevada qualidade" para "atingir, entre outros objetivos, o da educação para todos" (Idem, p. 165). E no contexto do documento, é função da Educação Superior (ES) realizar essa formação dos professores e a aproximação dos outros níveis de ensino por meio da pesquisa. Essa posição é tomada com a finalidade de estruturar a ES e a EB de forma mais coetânea ao tempo da denominada $3^{a}$ Revolução Industrial. O discurso, como vimos, "é que a educação formal é um fator essencial para o desenvolvimento econômico dos países pobres porque viabiliza o aumento do capital humano ${ }^{5}$ e a promoção do desenvolvimento individual e social" (NOMA; KOEPSEL; CHILANTE, 2010, p. 78).

É possível evidenciar, no Relatório Bindé, que as prioridades e recomendações para os países do sul do planeta são direcionadas à EB para todos. Os temas da produção do conhecimento, da ES e da formação de pesquisadores, estão presente nas discussões, porém, não há qualquer prescrição específica para essas áreas no item "Recomendações" que consta no final do documento. No nosso entender, a implementação dessas recomendações contribui para a permanência desses países em situação subordinada em relação ao eixo norte.

Em tese, são feitas, no Relatório, prescrições voltadas à reforma da educação e da C,T\&I, que garantiriam a consubstanciação das Sociedades do Conhecimento nos países periféricos. São elas: introduzir uma visão sistêmica na forma de elaborar as políticas; orientar-se para o desenvolvimento sustentável; produzir consenso por meio da participação de empresas, sociedade civil, instituições de ensino e pesquisa na formulação das políticas; aproximação entre a universidade e a EB, formando professores, desenvolvendo pesquisas em conjunto e readequando os currículos; defesa da EB de qualidade para todos; priorização, na EB, da matemática, do estudo de línguas e da educação científica voltada para a resolução de problemas. Essas recomendações do Relatório Bindé convergem para aquelas voltadas à educação e à C,T\&I, presentes nos Livros Verde (2001), Branco (2002) e Azul (2010), permitindo-nos afirmar que os pressupostos teóricoideológicos para a constituição das Sociedades do Conhecimento preconizados pela UNESCO permeiam os “Livros Coloridos" brasileiros. Por meio do Relatório Bindé e de outros, como o Relatório Delors, esse Organismo Internacional (OI) determina padrões, produz consensos universais, "constituindo-se em um fórum central disseminador de princípios e orientações gerais para políticas educacionais dos países-membros" (NOMA; KOEPSEL; CHILANTE, 2010, p. 69). E, como vimos, o determinismo do conhecimento científico e tecnológico é o argumento

5 Percebe-se aqui, de forma explícita, a incorporação da teoria do capital humano (SCHULTZ, 1961), como pressuposto, nas discussões das Sociedades do Conhecimento. 
ideológico central das reflexões do Relatório Bindé, com a finalidade de "controlar o metabolismo social" (MÉSZÁROS, 2006, p. 65) e direcionar as políticas para os interesses de acumulação do capital.

\section{A RELAÇÃO ENTRE POLÍTICA CIENTIIFICA E POLÍTICA EDUCACIONAL}

A visão sistêmica materializada nos três documentos nacionais analisados é comprovada com a busca de articulação entre política científica e política educacional. Os três livros apresentam um capítulo/tópico específico sobre a educação: no Livro Verde (2001): "Educação para ciência, tecnologia e inovação"; no Livro Branco (2002), a VII diretriz estratégica: "Educar para a sociedade do conhecimento"; nos dois volumes do Livro Azul, apresenta-se um capítulo específico sobre educação, afirmando que o "Brasil precisa de uma revolução na educação" (BRASIL/MCT/CGEE, 2010a, p. 97), e sobre o "Papel da C\&'T na promoção de uma educação de qualidade desde a primeira infância” (BRASIL/ MCT/CGEE, 2010b, p. 39, grifos nossos). Uma primeira convergência, comum a todos os documentos, é que a baixa escolaridade da população brasileira constitui obstáculo ao desenvolvimento da C\&T do país. E uma segunda é que os grandes projetos de C\&T requerem um elevado número de profissionais qualificados de nível técnico e superior. Portanto, a necessidade de formação desse contingente pressupõe educação de qualidade para todos os brasileiros em todos os níveis.

Porém, no Livro Azul (2010) há uma ampliação do diagnóstico, apontando que seria necessário superar algumas das consequências do processo de universalização do ensino fundamental, dentre elas: a remuneração irrisória dos professores; a formação deficiente; a consequente baixa qualidade do ensino; a infraestrutura precária das escolas; a duração reduzida do turno escolar; a falta de apoio à educação infantil em comunidades carentes, que dificulta a mobilidade social; a municipalização da educação, que, embora permita maior acompanhamento das escolas por parte da comunidade, dificulta a articulação de uma política nacional; o baixo índice de jovens entre 15 e 17 anos frequentando o ensino médio; e a elevada taxa de evasão dos alunos deste nível.

Podemos perceber que esse diagnóstico levanta os principais problemas da educação, mas não analisa os determinantes histórico-sociais que produziram essa situação. A estratégia de utilizar a expressão de que o país precisa de uma "revolução na educação" ou de que é preciso "educar para a sociedade do conhecimento" é uma forma de impactar, convencer que todos devem atuar para a conquista de uma educação de qualidade. Em outras palavras, os formuladores da política científica e educacional buscam consubstanciar um 
processo hegemônico "para consolidar um padrão de sociabilidade afinado com as necessidades do capitalismo contemporâneo" (MARTINS, 2009, p. 22). É uma concepção messiânica da educação, como se, por meio dela, fosse possível superar os entraves ao desenvolvimento social e econômico deste momento histórico, obnubilando ou obliterando a percepção das relações capital/trabalho como as produtoras dessa situação.

Os "Livros 'coloridos" podem ser caracterizados como documentos por meio dos quais propõem-se mudanças na educação que atendem predominantemente às necessidades do capital em termos de desenvolvimento da C,T\&I e de constituição de sociabilidades, portanto, de reforma do sistema e não de revolução no sentido de contribuir para a transformação de um modo de produção em outro (BOTTOMORE, 2001). Porém, segundo Martins (2009), no Governo Luiz Inácio Lula da Silva há um teor mais palatável ao social:

A valorização da educação escolar nos termos propostos pela 'direita para o social', além de responder aos requisitos da formação técnica mais elementar para o trabalho simples, procura também se converter numa importante referência de formação de valores e comportamentos sociais das futuras gerações de trabalhadores (p. 22).

Em relação ao discurso da educação de qualidade é preciso definir a substância desse conceito, pois não existe um critério universal de qualidade. Historicamente, existem diferentes parâmetros "que respondem a diversos critérios e intencionalidades políticas" (GENTILI, 1996). Com efeito, a definição da qualidade da educação "é um fenômeno complexo, abrangente, que envolve múltiplas dimensões" (DOURADO; OLIVEIRA ${ }^{6}, 2009$, p. 205), que, na análise dos Livros, como afirmamos, coadunam com as demandas de trabalho simples, da competitividade, da produtividade e da eficácia relacionadas ao processo de reestruturação produtiva e da divisão internacional do trabalho entre países e blocos produtores e adaptadores de conhecimento.

Depois do diagnóstico, há prescrições de medidas para melhorar a educação em geral e a científica em particular. No Governo Fernando Henrique Cardoso (FHC), que reproduz o discurso "de uma profissão de fé na Sociedade do Conhecimento" (MARI, 2006), é proposto: induzir um ambiente favorável a um aprendizado permanente; difundir a cultura científica e tecnológica na sociedade; expandir as condições de acesso e uso de Tecnologias da Informação e Comunicação (TIC) para os distintos segmentos da sociedade; instigar a utilização das TIC na universalização do acesso à educação científica e tecnológica; incentivar o envolvimento dos meios de comunicação na cobertura dos assuntos;

6 Para esses autores, a qualidade da educação compreende dimensões extra e intraescolares (DOURADO; OLIVEIRA, 2009). 
treinamento de professores; promoção de feiras de ciências, criação de museus (BRASIL/MCT, 2002). As medidas implementadas pelo Governo Luiz Inácio Lula da Silva são: o Plano Nacional de Formação de Professores da Educação Básica (PARFOR); o piso salarial nacional; as bolsas de estudo, para cursos de licenciatura, fornecidas pela NOVA CAPES - Programa Institucional de Bolsas de Iniciação à Docência (PIBID) ${ }^{7}$ e Programa Bolsas Jovens Talentos para a Ciência (PJT-IC) ${ }^{8}$; e a ICJ pelo CNPq. Essas iniciativas de fomento à pesquisa, de formação de pesquisadores e docentes, indicam um novo papel dessas agências de fomento, traduzidas na indução à aproximação entre as universidades e as escolas.

Nesse contexto, são feitas prescrições que possibilitariam ao país estabelecer um programa para os próximos anos e dar "um salto qualitativo e quantitativo no desenvolvimento da C,T\&I" (BRASIL/MCT/CGEE, 2010a, p. 100). No Livro Azul há uma profusão de recomendações para a educação, que demonstram maior organicidade, detalhamento e aprofundamento da relação entre ciência, tecnologia e educação no Governo Luiz Inácio Lula da Silva do que naquele do Governo Fernando Henrique Cardoso (FHC). Destacamos algumas das diretrizes econômicas, políticas e pedagógicas representativas deste documento. A primeira delas é a de que o Brasil deve atingir, em 2020, 10\% de investimento do Produto Interno Bruto (PIB) em educação. Esse aumento é visto como condição para a valorização salarial do professor, que teria renda compatível com a de outros profissionais, como médicos, engenheiros etc.

Existe a visão de que o Sistema Nacional de Educação (SNE) precisa de melhorias na gestão. Porém, para Cury (2008), o Brasil não logrou êxito em estabelecer um SNE, por duas razões: a primeira, de ordem histórico-social, relacionada à nossa desigualdade social; a segunda, de ordem jurídico-política, pela formação "histórica com que se revestiu nosso federalismo (o qual) gerou uma interpretação de que tal sistema ofenderia a autonomia dos entes federados estaduais e municipais" (p. 1187).

No que diz respeito à melhoria da gestão e do processo de governança, é recomendado no Livro Azul (2010): a necessidade de articulação de ações entre as diferentes esferas de governo, sociedades científicas, universidades e conselhos de educação, o que, como já vimos, também é recomendado no Livro Verde (2001) e no Livro Branco (2002); a criação de um sistema de certificação de competência

\footnotetext{
$7 \quad$ Ver a este respeito o texto de Ristoff e Bianchetti (2012).

8 Em 2012 a CAPES lançou o PJT-IC com a finalidade de preparar estudantes das fases inicias da graduação para o PIBIC, o PIBID e o Programa Ciências sem Fronteiras. Cf. <http://www.capes.gov.br/ images/stories/download/editais/Edital_026_2014_JTC.pdf $>$ Nesse sentido, podemos dizer que este órgão de fomento se somou ao processo de capilarização da IC. Porém, o foco, nesse texto, é o CNPq.
} 
docente que sirva de parâmetro para a concessão de prêmios e para a progressão na carreira docente; o apoio à implementação de Lei de Responsabilidade Educacional (PL7420/06) ${ }^{9}$, de autoria da Deputada Raquel Teixeira, que prevê a responsabilização e punição dos gestores públicos que não desencadearem ações que melhorem a qualidade da educação, o que é verificado por processos nacionais de avaliação escolar.

Há uma tentativa de ocultamento da dimensão política do processo de gestão em todos os documentos, centralizando-a nos preceitos do planejamento entre diferentes setores e níveis do governo, universidades e fóruns de discussão de ciência e educação, e o controle técnico na busca da melhoria da eficácia do sistema. Por isso, a necessidade do governo de responsabilizar os professores e gestores pelos resultados da educação, por meio de um sistema de certificação e de punição, como previsto na lei de responsabilidade educacional.

Em relação à formação dos professores, no Livro Azul (2010), assinala-se a importância das Instituições de Ensino Superior (IES) nesse processo, com a expansão de matrículas, principalmente para as áreas de ciência e matemática. Esse processo de priorização da ciência - que já havia sido indicado nos Livros Verde (2001), e Branco (2002), porém, de forma incipiente - e da matemática é constatado nas propostas de bolsas de formação, no aumento do número de aulas e na defesa da necessidade de atenção especial à aprendizagem das crianças e de adolescentes nessas áreas, consideradas fundamentais para a educação científica e tecnológica. Entre as razões da primazia das áreas da ciência e da matemática - consideradas estratégicas para o desenvolvimento C\&T - na formação de professores e no currículo da EB, destaca-se a falta de professores com essa formação específica e a busca de uma formação "para a solução de problemas imediatos, suscitados pela prática”, desde a Educação Infantil (SHIROMA, 2003, p. 63), no esforço de sedimentar a cultura da educação científica voltada à inovação.

Essas demandas estão voltadas para as necessidades de desenvolvimento da força produtiva do trabalho (FPT) no capitalismo, numa ambiência de reestruturação produtiva e intensa inserção de inovações tecnológicas. Para isso, no campo da educação, são consideradas necessárias a criação e difusão de inovações educacionais e de novas metodologias e a adoção e incorporação de novos materiais didáticos e das TD, objetivando a valorização da cultura da inovação e do empreendedorismo. Dessa forma, a educação tradicional, centrada

9 Esse projeto de lei ainda não foi aprovado. Porém, no Plano Nacional de Educação (PNE), em seu anexo "metas e estratégias", item 20.11, está prevista a aprovação da lei no prazo de um ano (BRASIL/MEC, 2014). 
no professor como o transmissor do acervo cultural aos alunos, tornou-se obsoleta; por isso, a necessidade de uma nova pedagogia, como afirma Moraes (2003):

O discurso é claro: é preciso, agora, elaborar uma nova pedagogia, um projeto educativo de outra natureza, e assegurar o desenvolvimento de competência, valor agregado a um processo que, todavia, não é o mesmo para todos (p. 152).

Podemos afirmar que, nas diretrizes dos Livros Azul (2010), Verde (2001) e Branco (2002), para a educação, há o predomínio de uma epistemologia pragmática, direcionada para as dificuldades imediatas do cotidiano escolar e/ ou necessidades do setor produtivo, em consonância com as discussões de Ball (2014). Dessa forma, identificam-se convergências/continuidades em termos de política científica e educacional voltada para a EB entre o Governo Fernando Henrique Cardoso (FHC) e o Governo Luiz Inácio Lula da Silva; porém, nesse último há maior aprofundamento, organicidade e detalhamento do diagnóstico e das prescrições. Nesse contexto, a Iniciação Científica Júnior (ICJ) é implementada pelo CNPq em 2003, como estratégia para iniciar a formação de pesquisadores nos anos finais do Ensino Fundamental (EF) e do Ensino Médio (EM) e induzir à aproximação entre as escolas e as universidades, como veremos em seguida.

\section{INICIAÇÃO CIENTIÍFICA JÚNIOR: ESTRATÉGIA DE APROXIMAÇÃO ENTRE AS UNIVERSIDADES E AS ESCOLAS}

Um dos principais objetivos da IC é a formação inicial de pesquisadores e a contribuição desta para a redução do tempo médio de titulação (TMT) de mestre e doutores. Em 2003, foi criada a modalidade de ICJ, por meio do Programa de Iniciação Científica Júnior (IC-Jr), que concede bolsas aos estudantes da EB com a finalidade de identificar, despertar e incentivar talentos para a carreira acadêmica e científica. Portanto, a IC e a ICJ são modalidades por meio das quais o CNPq mais investe na formação de investigadores, suas bolsas representando 60\% das bolsas de formação e qualificação no país em 2014. Esses dados podem "ser explicado[s] pela visão estratégica que a IC vem ganhando nas políticas de investimentos em ciência e tecnologia e formação inicial de jovens pesquisadores" (SANTOS, 2013, p. 48).

Os documentos nacionais de política científica analisados prescrevem a expansão dos programas de formação de pesquisadores como uma das maneiras de identificar talentos potenciais para o campo acadêmico, como demonstram estes excertos: "Em particular, a ampliação e a diversificação da formação de cientistas e engenheiros constituem condições essenciais para inserir a inovação na 
agenda econômica e social do País (BRASIL/MCT, 2002, p. 40, grifos nossos)"; e também: A expansão em termos quantitativos e qualitativos, da formação de recursos humanos em C,T\&I, em todos os níveis de ensino (BRASIL/MCT/ CGEE, 2010b, p. 29).

Pelo excerto do Livro Branco (2002), podemos perceber que a ampliação da política de formação de quadros para a pesquisa e a inovação foi gestada/ prescrita desde o Governo Fernando Henrique Cardoso (1992-2002). Porém, o Governo Luiz Inácio Lula da Silva (2003-2010), além de reproduzir no Livro Azul (2010) os argumentos teóricos para justificar a necessidade da expansão da formação de pessoas, aponta seu alargamento para a Educação Básica. As recomendações contidas nesse documento são explícitas - diferentemente dos outros - na perspectiva de ampliar os incentivos à pesquisa na EB por meio da iniciação científica e com projetos de pesquisa universidade-escola realizados na escola, "envolvendo professores e alunos como sujeitos da pesquisa, com a participação e/ou orientação de pesquisadores da universidade" (BRASIL/ MCT/CGEE, 2010b, p. 43). Isso, com a finalidade de descobrir e formar talentos necessários para o avanço da $C \& T$, o que pode contribuir para mudanças na estrutura curricular e pedagógica das escolas. Este é um dos diferenciais do Governo Luiz Inácio Lula da Silva em relação aos governos anteriores: a implementação da IC na EB justificada e recomendada no Livro Azul (2010) ${ }^{10}$.

Dessa forma, a função da educação - e aqui, da educação científica é constituir sociabilidades identificadas com o capital no plano valorativo, elevar o patamar de racionalidade da FPT e atrair "mais jovens para as carreiras científicas." (BRASIL/MCT/CGEE, 2010a, p. 19). Um dos pressupostos dos formuladores dessa política é o de que a formação do espírito científico na EB interfere na função investigadora na graduação e na pós-graduação. O docente do Ensino Fundamental e do Ensino Médio deve ser valorizado como professor pesquisador, transformando-se "em principal agente de desenvolvimento da ciência e tecnologia nas escolas." (BRASIL/MCT/CGEE, 2010b, p. 40). Uma das implicações dessa posição é a de que prevaleça uma perspectiva de formação e de práxis de formação do professor pesquisador, de produção do conhecimento limitada ao pragmatismo e um encaminhamento teórico-metodológico que fique restrito à prática, ao contexto particular, que pode apontar para o "recuo da teoria." (MORAES, 2003).

10 Para um aprofundamento a este respeito, ver a tese de Oliveira (2015). 


\section{CONSIDERAÇÕES FINAIS}

Como podemos verificar, os Governos Fernando Henrique Cardoso (FHC) e Luiz Inácio Lula da Silva, por meio da construção dos Livros Verde (2001), Branco (2002) e Azul (2010) buscaram, em termos conceituais, articular suas políticas de C,T\&I, tendo como parâmetros: inovação tecnológica; desenvolvimento sustentável; visão sistêmica; governança. Para construir o consenso em torno desses eixos e das prescrições dos documentos, foram envolvidos nessa discussão: governo, associações científicas, setor empresarial, sindicatos, estudantes, representantes dos governos federal, estaduais e municipais, terceiro setor e organismos internacionais. Porém, no Governo Luiz Inácio Lula da Silva, há uma radicalização do discurso do diálogo social entre capital e trabalho para elaborar e implementar essas políticas amparado no conceito de sociedade civil.

Neste momento histórico, um fato determinante para a implementação dessas políticas é a necessidade constante do capital de inovações de produtos e processos de produção como condição para o desenvolvimento da FPT. Para isso, apregoa-se, é necessário que se faça uma "revolução na educação" na direção da "sociedade do conhecimento", envolvendo a abordagem pedagógica, a estrutura curricular, a formação de professores e a gestão. O estratagema de afirmar que o país precisa de uma "revolução na educação" é uma forma de convencer que todos devem operar para que conquistemos uma educação de qualidade. Essa visão messiânica da educação não se sustenta na materialidade, pois a humanidade necessita buscar ainda saídas para a superação da contradição capital/trabalho.

A recomendação, no Livro Azul, de ampliação de incentivos à pesquisa na $\mathrm{EB}$, por meio da iniciação científica e com projetos de pesquisa universidadeescola realizados na escola, demonstra que a intenção do Governo Luiz Inácio Lula da Silva era descobrir e formar talentos necessários para o avanço da C\&T e poder contribuir para mudanças na estrutura curricular e pedagógica das escolas. E a política do CNPq, de ampliar a oferta de bolsas de IC para a EB, pode estar induzindo a um processo de diminuição da distância entre o ensino da graduação e o da EB, assim como pretendeu diminuir a distância entre a graduação e a pósgraduação com o PIBIC. Para Falleiros, Pronko e Oliveira (2010, p. 90), o que se busca por meio dessa política para a Educação Básica é que se preparem os jovens "para a incorporação e o manejo das novas tecnologias."

Ambos os Governos, por meio dos Livros Verde (2001), Branco (2002) e Azul (2010), afirmam a centralidade do conhecimento para a inserção competitiva dos países, blocos econômicos e empresas no mercado mundial, articulados ao desenvolvimento sustentável e ao reconhecimento das desigualdades no acesso 
a esses conhecimentos e tecnologias e a seu domínio. Além disso, apresentam convergência na política científica proposta quanto à articulação da política científica e educacional e à priorização e expansão da IC. Nesse contexto, compete ao Estado "estimular a capacitação tecnológica, definir diretrizes, gerar infraestrutura necessária à interação entre os agentes envolvidos e estabelecer um vínculo estreito entre políticas de ciência e tecnologia e políticas educacionais" (SILVEIRA, 2015, p. 40). Porém, o Governo Luiz Inácio Lula da Silva aponta maior detalhamento dessas recomendações no Livro Azul (2010) e acrescenta a necessidade e importância da implementação da IC no EM. O Governo Dilma Rousseff (2011-2016) deu continuidade a essa política, com a priorização da IC e com a expansão da ICJ. Por fim, podemos afirmar que os livros 'Coloridos' convergem no que se refere aos pressupostos teórico-metodológicos e às recomendações do Relatório Bindé da UNESCO, que apontam, como vimos, para a inserção subordinada dos países que se encontram fora do polo dinâmico do capital nas Sociedades do Conhecimento.

\section{REFERÊNCIAS}

BALL, S. J. Educação global S.A. Novas redes políticas e o imaginário neoliberal. Ponta Grossa: Editora UEPG, 2014.

BIANCHETTI, L.; QUARTIEIRO, E. M. Tecnologias digitais na pós-graduação: estratégias de incorporação no ensino e na orientação. Série-Estudos (PPGE/ UCDB), Campo Grande, n. 32, p. 139-155, jul./dez. 2011.

BINDÉ, J. (Coor.). Rumo às sociedades do conhecimento: relatório mundial da UNESCO. Lisboa: UNESCO/Instituto Piaget, 2007.

BOTTOMORE, T. (Editor). Dicionário do pensamento marxista. Rio de Janeiro: Jorge Zahar Ed., 2001.

BRASIL/MCT/ABC. Livro verde de ciência tecnologia e inovação: desafio para a sociedade brasileira. Brasília: MCT, 2001.

BRASIL/MCT. Livro Branco: ciência, tecnologia e inovação. Brasília: MCT, 2002. 
BRASIL/MCT/CGEE. Ministério da Ciência, Tecnologia e Inovação/Centro de Gestão e Estudos Estratégicos. Livro Azul: 4ª Conferência Nacional de Ciência, Tecnologia e Inovação para o Desenvolvimento Sustentável. BrasíliA: MCT, 2010 a.

Consolidação das Recomendações da $4^{a}$ Conferência Nacional de Ciência, Tecnologia e Inovação para o Desenvolvimento Sustentável. Brasília: MEC, 2010b.

BRASIL/MEC. Lei n. 13.005, de 25 de junho de 2014. Diário Oficial da União, Ano CLI, n. 120-A, Brasília: Imprensa Nacional, 2014.

CURY, C. R. J. Sistema nacional de educação: desafio para uma educação igualitária e federativa. Educação \& Sociedade, Campinas, vol. 29, n. 105, p. 1187-1229, set./dez. 2008.

DOURADO, L. F; OLIVEIRA, L. F. de. A qualidade da educação: perspectivas e desafios. Cadernos Cedes, Campinas, v. 29, n. 78, p. 201-215, maio/ago. 2009.

FALLEIROS, I.; PRONKO, M. A.; OLIVEIRA, M. T. C. de. Fundamentos Históricos da formação/atuação dos intelectuais da nova pedagogia da hegemonia. In. NEVES, L. M.W. (Org.) A direita para o social e a esquerda para o capital. Intelectuais da nova pedagogia da hegemonia no Brasil. São Paulo, Xamã, 2010.

GENTILI, P. A. A. O discurso da "qualidade" como nova retórica conservadora no campo educacional. In: ; SILVA, T. T. da (Org.). Neoliberalismo, qualidade total e educação. 4 ed. Petrópolis: Vozes, 1996. p. 111-177.

MARI, C. L. de. "Sociedade do Conhecimento" e Educação Superior na década de 1990: O Banco Mundial e a produção do desejo irrealizável de Midas. 2006. 265 f. Tese (Doutorado em Educação) - Universidade Federal de Santa Catarina, Florianópolis.

MARTINS, A. S. A Educação Básica no século XXI: o projeto do organismo “Todos pela Educação”. Práxis Educativa, Ponta Grossa, v. 4, n. 1, p. 21-28. Jan./jun., 2009.

MÉSZÁROS, I. O poder da ideologia. São Paulo: Boitempo, 2006. 
MORAES, M. C. M. de. Recuo da Teoria. In: - (Org.). Iluminismo às avessas: produção de conhecimento e políticas de formação docente. Rio de Janeiro: DP\&A, 2003. p. 151-167.

NOMA, A. K.; KOEPSEL, E. C. N.; CHILANTE, E. F. N. Trabalho e educação em documentos de políticas educacionais. Revista HISTEDBR On-line, Campinas, número especial, p. 65-82, ago. 2010. Disponível em: <http://www. histedbr.fe.unicamp.br/revista/edicoes/38e/art05_38e.pdf>. Acesso em: 19 maio 2015.

OLIVEIRA, A. de. A Iniciação Científica Júnior (ICJ): aproximações da Educação Superior com a Educação Básica. 2015. 322 f. Tese (Doutorado em Educação) - Universidade Federal de Santa Catarina, Florianópolis, 2015.

RISTOFF, D; BIANCHETTI, L. A pós-graduação e suas interlocuções com a educação básica. (Des)encontros históricos e manutenção do apartheid socioeducacional. Avaliação. Revisa da Avaliação da Educação Superior. Campinas; Sorocaba, v. 17, n. 3, p. 767-806, nov. 2012.

SANTOS, S. A. dos. Mudanças na graduação na universidade pública: a nova prática da iniciação científica. 2013. 126 f. Tese (Doutorado em Educação) Centro de Educação. Universidade Federal de São Carlos, São Carlos, 2013.

SCHULTZ, T. W. Investiment in human capital. The American Economic Review, v. LI, n. 1, p. 1-17, march, 1961.

SHIROMA, E. O. O eufemismo da profissionalização. In: MORAES, M. C. M. de. (Org.). Iluminismo às avessas: produção de conhecimento e políticas de formação docente. Rio de Janeiro: DP\&A, 2003. p. 61-79.

SILVEIRA, Z. S. Formação científica no nível médio de ensino: primeiras aproximações. Boletim Técnico Senac, Rio de Janeiro, v. 41, n. 1, p. 36-57, jan./ abr. 2015.

ADRIANO DE OLIVEIRA é mestre (2003) e doutor (2015) em Educação pela Universidade Federal de Santa Catarina. Estágio doutoral no ICS/UMINHO (2013). Coordenador Pedagógico na Rede Municipal de Ensino de Florianópolis. Membro do Grupo de Estudos Trabalho e Conhecimento na Educação Superior (TRACES/UFSC/CNPq). E-mail: adriano.deoliveira2@gmail.com 
LUCÍDIO BIANCHETTI é Pedagogo (UPF/RS), Mestre em Educação (PUC-Rio) e Doutor em Educação: História, Política e Sociedade (PUC/SP). Estágio pósdoutoral (Universidade do Porto, PT). Professor (aposentado/voluntário) na Universidade Federal de Santa Catarina. Ex-Coordenador do PPGE/UFSC. Ex-vice-presidente da ANPEd. Pq 1B do CNPq. E-mail: lucidio.bianchetti@, pq.cnpq.br 